\title{
Towards a Global Understanding and Standardisation of Education and Training in Microsurgery
}

\author{
Clement Chi Ming Leung ${ }^{1}$, Ali M Ghanem ${ }^{1}$, Pierluigi Tos ${ }^{2}$, Mihai Ionac ${ }^{3}$, Stefan Froschauer ${ }^{4}$, \\ Simon R Myers ${ }^{1}$ \\ ${ }^{1}$ Academic Plastic Surgery Group, Barts and The London School of Medicine and Dentistry, London, UK; ${ }^{2}$ Department of Reconstructive \\ Microsurgery, Orthopaedic and Trauma Centre-CTO Hospital, Turin, Italy; ${ }^{3}$ Division of Vascular Surgery and Microsurgery, Victor Babes \\ University of Medicine and Pharmacy, Timisoara, Romania; ${ }^{4}$ Microsurgical Training and Research Centre, Centre for Biomedical Technology \\ and Research, Linz, Austria
}

With an increasing emphasis on microsurgery skill acquisition through simulated training, the need has been identified for standardised training programmes in microsurgery. We have reviewed microsurgery training courses available across the six continents of the World. Data was collected of relevant published output from PubMed, MEDLINE (Ovid), and EMBASE (Ovid) searches, and from information available on the Internet of up to six established microsurgery course from each of the six continents of the World. Fellowships and courses that concentrate on flap harvesting rather than microsurgical techniques were excluded. We identified 27 centres offering 39 courses. Total course length ranged from 20 hours to 1,950 hours. Studentto-teacher ratios ranged from 2:1 to 8:1. Only two-thirds of courses offered in-vivo animal models. Instructions in microvascular end-to-end and end-to-side anastomoses were common, but peripheral nerve repair or free groin flap transfer were not consistently offered. Methods of assessment ranged from no formal assessment, where an instructor monitored and gave instant feedback, through immediate assessment of patency and critique on quality of repair, to delayed re-assessment of patency after a 12 to 24 hours period. Globally, training in microsurgery is heterogeneous, with variations primarily due to resource and regulation of animal experimentation. Despite some merit to diversity in curricula, there should be a global minimum standard for microsurgery training.

Keywords Curriculum / Education / Microsurgery / Teaching
Correspondence: Ali M Ghanem Academic Plastic Surgery Group, Centre for Cutaneous Research, Blizard Institute, Barts and The London School of Medicine and Dentistry, 4 Newark Street, London E1 2AT, UK

Tel: +44-77-64-18-44-77

Fax: +44-87-08-38-14-74

E-mail: a.ghanem@qmul.ac.uk

Source of fund: STeLI London Deanery.

The authors would like to acknowledge Professor Nigel Stanfield and the London School of Surgery for their support of this project.

This article was presented at the Inaugural Meeting of the International Microsurgery Simulation Society on June 30, 2012 at the Queen Mary, University of London Mile End Campus, in London, UK.

No potential conflict of interest relevant to this article was reported.

Received: 10 Feb 2013 • Revised: 15 Mar 2013 • Accepted: 16 Apr 2013

plSSN: 2234-6163 • elSSN: 2234-6171 • http://dx.doi.org/10.5999/aps.2013.40.4.304 • Arch Plast Surg 2013;40:304-311

\section{INTRODUCTION}

Microsurgery is a fundamental technique in the armamentarium of the reconstructive surgeon, key to vascular anastomoses, neurorrhaphies, and lymphatic anastamoses. It is an essential component of an increasing number of surgical specialties since it's birthplace in Plastic Surgery. To become proficient in microsurgery, attendance at instructional microsurgery courses has become a popular, augmenting the apprenticeship model of learning in the operating theatre. Training facilities in micro- 
surgery are found throughout the World [1-9], and the aim of any basic microsurgery course is to introduce the fundamental techniques required for microsurgical dissection and anastomosis. Completion of a course does improve microsurgical skills within a short time period in most trainees [10]. However in one study of trainees who attended a 1 week microsurgery training course $60 \%$ had improved, $10 \%$ had remained the same, and $30 \%$ had got worse when assessed using global rating scales of microvascular anastomoses [11]. A further study found that those completing a microsurgical course or fellowships were not necessarily able to complete a vascular anastomosis at a satisfactory rate of patency [12].

With the increasing use of microsurgical techniques and with the variety of training courses available, there is a need for standardisation. We conducted a review to compare the present courses in microsurgery available around the world as a foundation to the development of an International quality standard.

\section{METHODS}

Information was obtained from: 1) a systematic literature search within the database PubMed, MEDLINE (Ovid) and EMBASE (Ovid) published in the last 20 years (1992 to 2012); 2) a comprehensive search within the Internet; 3 ) a survey on teaching microsurgery distributed amongst microsurgery trainers.

The names of up to six established microsurgery training centres in microvascular anastomoses from each of the six continents (Africa, Asia, Australasia, Europe, North America, and South America) were identified. Fellowships and courses that emphasise only flap harvesting were excluded. A questionnaire was distributed to microsurgery trainers based around the world. The questionnaire supplemented the information found on the Internet and the systematic literature search. It asked how many days courses ran, how many hours per day of course, what material was used in training, what was the training progression, was there any course evaluation, was there a final examination, and what was the cost of attending a course.

The results were organised into a database containing two parts. The first part established the characteristics of the training course, such as the duration, the student-to-trainer ratios, and the cost of the course offered. The second part determined the specific content of the training course, such as which technical aspects of microsurgery were taught, and the method of assessment.

\section{RESULTS}

Those centres reviewed offered a basic course in microsurgery, with some offering an additional advanced course for the more experienced surgeon. We received questionnaire responses from Europe and America. Overall, we identified 27 centres in six continents offering 39 courses (Africa: two centres, three courses; Asia: six centres, nine courses; Australasia: one centre, one course; Europe: six centres, eleven courses; North America: six centres, nine courses; South America: four centres, five courses; and one international course) (Tables 1,2).

\section{Characteristics of the courses}

The duration of course ranged from 20 hours to 1950 hours, and divided into categories of less than 35 hours, 35 to 45 hours ( 5 day period), and more than 45 hours (Fig. 1). The median duration of a course was 40 hours.

The number of trainees differed for each course, and some only permitted 3 trainees, whilst another programme accommodated 25 trainees. The trainee-to-trainer ratio ranged from 2:1 to 8:1 (average between 3:1 and 4:1).

The cost of attending a basic microsurgery course, excluding travel, accommodation, and food, ranged from 300 USD to 2,400 USD (mean 1,236 USD), and averaged approximately 260 USD per day. In contrast, the cost of attending an advanced microsurgery course ranged from 700 USD to 13,200 USD (mean 2,328 USD), and averaged approximately 296 USD per day.

\section{Contents of the courses}

The 39 courses found were divided into two main groups: A and B. Type A are basic courses that emphasise the fundamental principles of the practice of microsurgical techniques, including the use of the operating room microscope, micro-instruments, micro-sutures, and are identical for all trainees regardless of their surgical specialty. Type B are advanced courses that build upon previous experience, allow trainee to revise fundamental microsurgical techniques, and provide an opportunity to learn additional microsurgical techniques applicable to a trainee's specialty. Nearly all the centres reviewed offered a type A course, and 12 of the 27 centres also offered a type $B$ course.

In type A courses (Table 3) (Fig. 2), 86\% offered practice on non-living models such as the latex glove, practice card and silicone tubing as a starting point in training. $52 \%$ offered practice of anastomosis in larger arteries ( $>1 \mathrm{~mm}$ diameter), such as the rat aorta or carotid artery, and $96 \%$ offered practice on anastomosis in smaller arteries ( $\leq 1 \mathrm{~mm}$ diameter), such as the femoral artery. Venous anastomosis training was available in $91 \%$ of type A courses, and the vessels offered included the internal jugular vein, infrahepatic vena cava, and femoral vein ( 0.9 to $1.3 \mathrm{~mm}$ diameter). Ex-vivo animal models often used in 39\% of type A courses included chicken legs, cryo-preserved rat aortas, 
Table 1. Comparison of characteristics of basic microsurgery courses

\begin{tabular}{|c|c|c|c|c|c|}
\hline Institution & Duration & $\begin{array}{l}\text { Maximum } \\
\text { trainees }\end{array}$ & $\begin{array}{l}\text { Trainee: } \\
\text { trainer ratio }\end{array}$ & Cost USD & $\begin{array}{l}\text { Cost } \\
\text { USD/day }\end{array}$ \\
\hline \multicolumn{6}{|l|}{ Africa } \\
\hline Zagazig University Hand Microsurgery Center, Cairo, Egypt & 40 hr (5 day) & Not stated & Not stated & 1,000 & 200 \\
\hline Stellenbosch University, Tygerberg Hospital, South Africa & 24-32 hr (3 or 4 day) & Not stated & Not stated & 300 or 350 & 100 or 88 \\
\hline \multicolumn{6}{|l|}{ Asia } \\
\hline Chinese University of Hong Kong, Hong Kong & 20 hr (5 half day) & Not stated & Not stated & 520 & 104 \\
\hline Ganga Microsurgery Training Institute, Coimbatore, India & $40 \mathrm{hr}$ (5 day) & 4 & $2: 1$ & 750 & 150 \\
\hline $\begin{array}{l}\text { King Faisal Specialist Hospital and Research Centre, } \\
\text { Saudi Arabia }\end{array}$ & $40 \mathrm{hr}$ ( 5 day) & 7 & Not stated & Not stated & Not stated \\
\hline National University Hospital, Singapore & $44 \mathrm{hr}$ (5 day) & 4 & $2-4: 1$ & 1,000 & 200 \\
\hline Singapore General Hospital, Singapore & $40 \mathrm{hr}$ (5 day) & 20 & $6: 1$ & 1,200 & 240 \\
\hline Gulhane Military Medical Academy, Turkey & $45 \mathrm{hr}$ (5 day) & 5 & $3-5: 1$ & Not stated & Not stated \\
\hline \multicolumn{6}{|l|}{ Australasia } \\
\hline Microsearch Laboratory, University of Sydney, Sydney & $40 \mathrm{hr}$ (5 day) & 12 & Not stated & Not stated & Not stated \\
\hline \multicolumn{6}{|l|}{ Europe } \\
\hline $\begin{array}{l}\text { Erasmus MC, Universitair Medisch Centrum Rotterdam, } \\
\text { Netherlands }\end{array}$ & $40 \mathrm{hr}$ (5 day) & 6 & $2: 1$ & 2,100 & 420 \\
\hline $\begin{array}{l}\text { Pius Branzeu Center, Victor Babes University, Timisoara, } \\
\text { Romania }\end{array}$ & $32 \mathrm{hr}$ (3.5 day) & $14-17$ & $3: 1$ & 910 & 260 \\
\hline $\begin{array}{l}\text { Ecole de Chirurgie de L'Assistance Publique-Hospitaux de } \\
\text { Paris, France }\end{array}$ & $20 \mathrm{hr}$ (3 day) & 11 & $11: 2$ & 320 & 107 \\
\hline Maz Microsurgical Training Center, Linz, Austria & $24 \mathrm{hr}$ (3 day) & 18 & $4: 1$ & 800 & 267 \\
\hline Centro Traumatologico Ortopedico, Torino, Italy & 5 day & 20 & $4: 1$ & $800-1,600$ & $160-320$ \\
\hline Norwich Park Institute for Medical Research, UK & $35-40 \mathrm{hr}$ (5 day) & 16 & $8: 1$ & 2,400 & 480 \\
\hline \multicolumn{6}{|l|}{ North America } \\
\hline University of Louisville, Kentucky, USA & $35-40 \mathrm{hr}$ ( 5 day) & 4 & $4: 1$ & 2,000 & 400 \\
\hline Mayo Clinic Campus, Minnesota, USA & $40 \mathrm{hr}$ (5 day) & 4 & $4: 1$ & 1,875 & 375 \\
\hline Columbia University, New York, USA & $35-40 \mathrm{hr}$ ( 5 day) & 3 & $3: 1$ & 1,900 & 380 \\
\hline Indiana University Medical Center, Indiana, USA & $40 \mathrm{hr}$ (5 day) & Not stated & Not stated & 1,500 & 300 \\
\hline MOET Institute, c/o The Buncke Clinic, California, USA & 40 hr (5 day) & Not stated & Not stated & $950-1,500$ & $190-300$ \\
\hline McMaster University, Ontario, Canada & 40 hr (5 days) & Not stated & Not stated & 2,000 & 400 \\
\hline \multicolumn{6}{|l|}{ South America } \\
\hline Instituto de Ortopedia e Traumatologia, Sao Paulo, Brazil & $40 \mathrm{hr}$ (5 day) & 5 & Not stated & 1,000 & 200 \\
\hline Instituto Nacional do Cancer, Rio de Janeiro, Brazil & $100 \mathrm{hr}$ (25 day) & Not stated & Not stated & Not stated & Not stated \\
\hline Hospital Universitario Walter Cantidio, Fortaleza, Brazil & $60 \mathrm{hr}$ & Not stated & Not stated & Not stated & Not stated \\
\hline
\end{tabular}

and porcine coronary arteries. $90 \%$ used in vivo animal models, in particular the anaesthetised rat. All type A courses provided instructions in microvascular end-to-end anastomoses, and 78\% provided instructions in end-to-side anastomoses. Instruction in interposition vein grafting, peripheral nerve repair, or flap transfer were offered by $82 \%, 48 \%$, and $22 \%$ of type A courses, respectively (Table 3, Fig. 3).

In type $\mathrm{B}$ courses, course duration ranged from 12 hours to 1,950 hours. One centre offered a flexible duration tailored to trainee requirements. All courses offered revision of basic microsurgery techniques. Additional instruction included complete replantation of rabbit ears, groin free flap transfer using the femoral vessels or superficial inferior epigastric vessels as recipient vessels. Some also offered specialty-orientated instruction, such as vasovasostomy and vasoepididymostomy for urology trainees, fallopian tube anastomosis for obstetric and gynaecology trainees, and organ transplantation models (renal) for transplantation surgeons.

The different assessment methods were found, and we categorised them into: 1) No formal assessment-where an instructor monitored progress and gave feedback and subjective skill evaluation throughout the course; 2 ) Immediate assessment of vessel patency-after a 30 minutes to 2 hours period; 3 ) Delayed reassessment of vessel patency-after a 12 to 24 hours period.

Seventy-five percent of type A courses had no formal assessment. Five centres (21\%) evaluated the patency of microvascular anastomosis at 30 minutes to 2 hours post-intervention, and if unsuccessful, trainees had to repeat the assessment. Proficiency tests involved completion of both femoral arterial and venous anastomoses within a specific time frame. Only one centre 
Table 2. Comparison of characteristics of advanced microsurgery courses

\begin{tabular}{|c|c|c|c|c|c|}
\hline Institution & Duration & $\begin{array}{l}\text { Maximum } \\
\text { trainees }\end{array}$ & $\begin{array}{l}\text { Trainee: } \\
\text { trainer ratio }\end{array}$ & Cost USD & $\begin{array}{l}\text { Cost } \\
\text { USD/day }\end{array}$ \\
\hline $\begin{array}{l}\text { European School of Reconstructive Microsurgery, } \\
\text { International Faculty }\end{array}$ & $1,950 \mathrm{hr}(2 \mathrm{yr})$ & $9-25$ & Not stated & $7,900-13,200$ & Not stated \\
\hline Zagazig University Hand Microsurgery Center, Cairo, Egypt & 40 hr (5 day) & Not stated & Not stated & 1,000 & 200 \\
\hline Chinese University of Hong Kong, Hong Kong & 22 hr (5 half day) & Not stated & Not stated & 770 & 154 \\
\hline $\begin{array}{l}\text { King Faisal Specialist Hospital and Research Centre, } \\
\text { Saudi Arabia }\end{array}$ & $14-21 \mathrm{hr}(2-3$ day) & 7 & Not stated & Not stated & Not stated \\
\hline National University Hospital, Singapore & $26 \mathrm{hr}$ (3 day) & $3-4$ & $2-4: 1$ & 1,000 & 333 \\
\hline Pius Branzeu Center, Victor Babes University, Romania & 3 day (or more) & Not stated & Not stated & Not stated & 120 \\
\hline $\begin{array}{l}\text { Ecole de Chirurgie de l'Assistance Publique-Hospitaux de Paris, } \\
\text { France }\end{array}$ & $120 \mathrm{hr}(8 \mathrm{mo})$ & Not stated & Not stated & 800 & Not stated \\
\hline Maz Microsurgical Training Center, Linz, Austria & 16 hr (2 day) & 10 & $4: 1$ & 800 & 267 \\
\hline Azienda Ospedaliera Di Rilievo Nazionale, Napoli, Italy & $124 \mathrm{hr}(15$ day) & 15 & Not stated & 3,200 & 213 \\
\hline Norwick Park Institute for Medical Research, UK & $40 \mathrm{hr}$ (5 day) & Not stated & Not stated & 3,200 & 640 \\
\hline Columbia University, New York, USA & $40 \mathrm{hr}$ (5 day) & 3 & $3: 1$ & 1,700 & 340 \\
\hline Indiana University Medical Center, Indiana, USA & $12 \mathrm{hr}$ (2 day) & Not stated & Not stated & 900 & 450 \\
\hline MOET Institute, c/o The Buncke Clinic, California, USA & 40 hr (5 day) & Not stated & Not stated & $950-1,500$ & $190-300$ \\
\hline Argentina Association of Hand Surgery, Argentina & $20 \mathrm{hr}$ (3 day) & Not stated & Not stated & 700 & 233 \\
\hline Instituto de Ortopedia e Traumatologia, Sao Paulo, Brazil & $40 \mathrm{hr}$ (5 day) & 5 & Not stated & 1,500 & 300 \\
\hline
\end{tabular}

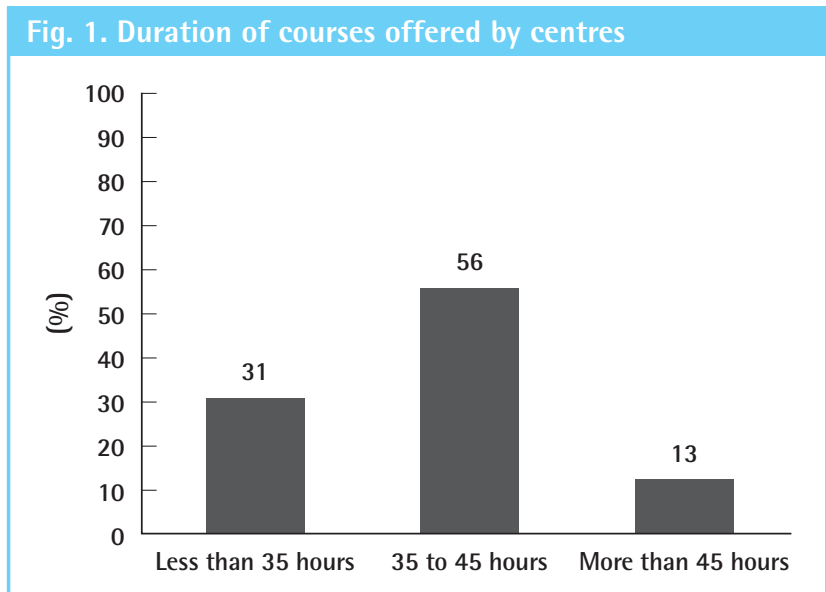

also assessed trainees with a previously published global rating scale (GRS), with a final grade calculated based on microsurgical technique and time taken. One centre (4\%) inspected the previous day's vascular repair for vessel patency, which allowed an opportunity to discuss reasons for thrombosis and to correct any technical errors.

\section{DISCUSSION}

Microsurgery training across the World is heterogeneous. Courses vary in duration, but most of the centres identified offered a 35 to 45 hours ( 5 days) training schedule. Some offered an advanced course in addition to a basic course. There was considerable variation in the trainee-to-trainer ratio, which may prove

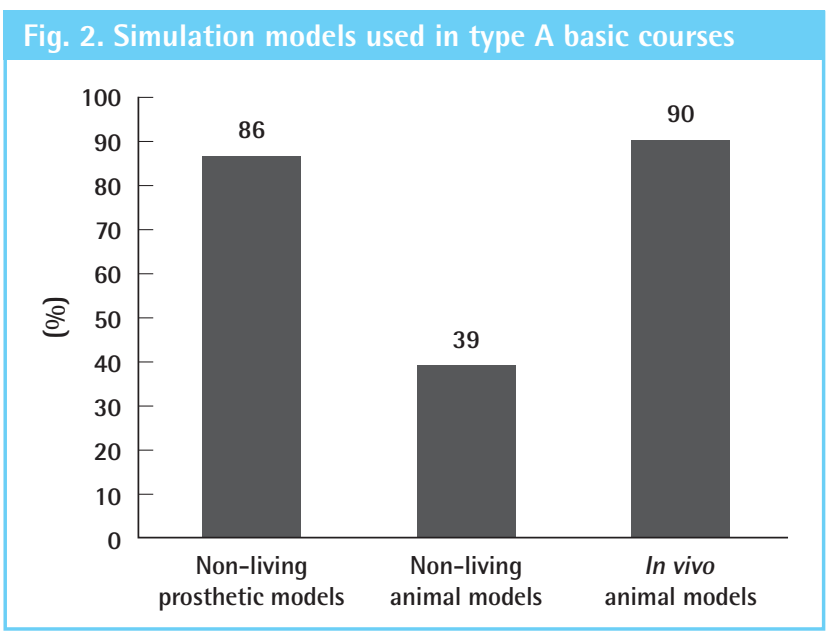

to have an effect on the trainee's learning through immediate feedback.

$E x$-vivo prosthetic models such as the latex glove, silicone sheets and tubing, although not offered by all, were a common starting point in training. This was generally followed by a variety of nonliving animal models, such as the porcine coronary artery, and chicken leg artery. Majority of courses offered in vivo animal models. The advantages of non-living and prosthetic models are: portability, minimal maintenance over a favourable shelf life, and with no biological hazards or regulations for their use-but they may not be as realistic as living models [13]. Silicone tubes simulating small blood vessels can be useful to practice handling microvascular instruments and for novices to familiarise themselves with microsurgical techniques, and perhaps for periodic 
Institution

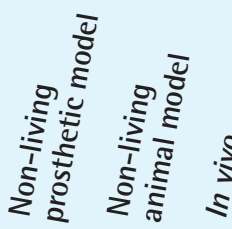

Zagazig University Hand Microsurgery Center, Cairo, Egypt Stellenbosch University, Tygerberg Hospital, South Africa Chinese University of Hong Kong, Hong Kong Ganga Microsurgery Training Institute, Coimbatore, India King Faisal Specialist Hospital and Research Centre, Saudi Arabia

National University Hospital, Singapore

Singapore General Hospital, Singapore

Gulhane Military Medical Academy, Turkey

Microsearch Laboratory, University of Sydney, Sydney

Erasmus MC, Universitair Medisch Centrum Rotterdam, Netherlands

Pius Branzeu Center, Victor Babes University, Timisoara, Romania

Ecole de Chirurgie de L'Assistance Publique-Hospitaux de Paris, France

Maz Microsurgical Training Center, Linz, Austria

Centro Traumatologico Ortopedico, Torino, Italy

Norwich Park Institute for Medical Research, UK

University of Louisville, Kentucky, USA

Mayo Clinic Campus, Minnesota, USA

Columbia University, New York, USA

Indiana University Medical Center, Indiana, USA

MOET Institute, c/o The Buncke Clinic, California, USA

McMaster University, Ontario, Canada

Instituto de Ortopedia e Traumatologia, Sao Paulo, Brazil

Instituto Nacional do Cancer, Rio de Janeiro, Brazil

Hospital Universitario Walter Cantidio, Fortaleza, Brazil

\begin{tabular}{|c|c|c|c|c|c|c|c|c|c|}
\hline Yes & - & Yes & No & Yes & Yes & Yes & Yes & No & No \\
\hline Yes & - & Yes & Yes & Yes & Yes & No & Yes & Yes & No \\
\hline Yes & - & Yes & Yes & Yes & No & No & No & No & Yes \\
\hline Yes & Yes & Yes & No & Yes & Yes & Yes & Yes & No & No \\
\hline Yes & No & Yes & Yes & Yes & Yes & Yes & Yes & Yes & No \\
\hline Yes & No & Yes & Yes & Yes & Yes & Yes & Yes & No & No \\
\hline Yes & No & Yes & Yes & Yes & Yes & Yes & Yes & Yes & Yes \\
\hline No & - & - & Yes & Yes & No & Yes & Yes & No & No \\
\hline- & - & - & - & - & - & - & - & - & - \\
\hline No & No & Yes & Yes & Yes & Yes & Yes & Yes & No & Yes \\
\hline Yes & Yes & Yes & Yes & Yes & Yes & Yes & Yes & Yes & No \\
\hline Yes & No & Yes & Yes & Yes & Yes & No & Yes & No & No \\
\hline No & Yes & Yes & No & Yes & Yes & Yes & No & Yes & No \\
\hline Yes & Yes & No & No & Yes & Yes & Yes & Yes & No & No \\
\hline Yes & No & Yes & No & Yes & Yes & Yes & Yes & Yes & Yes \\
\hline Yes & No & Yes & No & Yes & Yes & Yes & Yes & No & No \\
\hline Yes & No & Yes & Yes & Yes & Yes & Yes & Yes & Yes & No \\
\hline Yes & No & Yes & No & Yes & Yes & Yes & Yes & Yes & No \\
\hline Yes & No & Yes & No & Yes & Yes & Yes & Yes & Yes & No \\
\hline- & - & - & - & Yes & Yes & Yes & Yes & Yes & No \\
\hline Yes & No & Yes & No & Yes & Yes & Yes & Yes & No & Yes \\
\hline Yes & Yes & - & - & Yes & Yes & No & No & No & No \\
\hline Yes & Yes & Yes & Yes & No & Yes & Yes & Yes & Yes & No \\
\hline Yes & Yes & No & No & Yes & Yes & No & No & No & No \\
\hline
\end{tabular}

\section{Fig. 3. Instructions offered by type A basic courses}

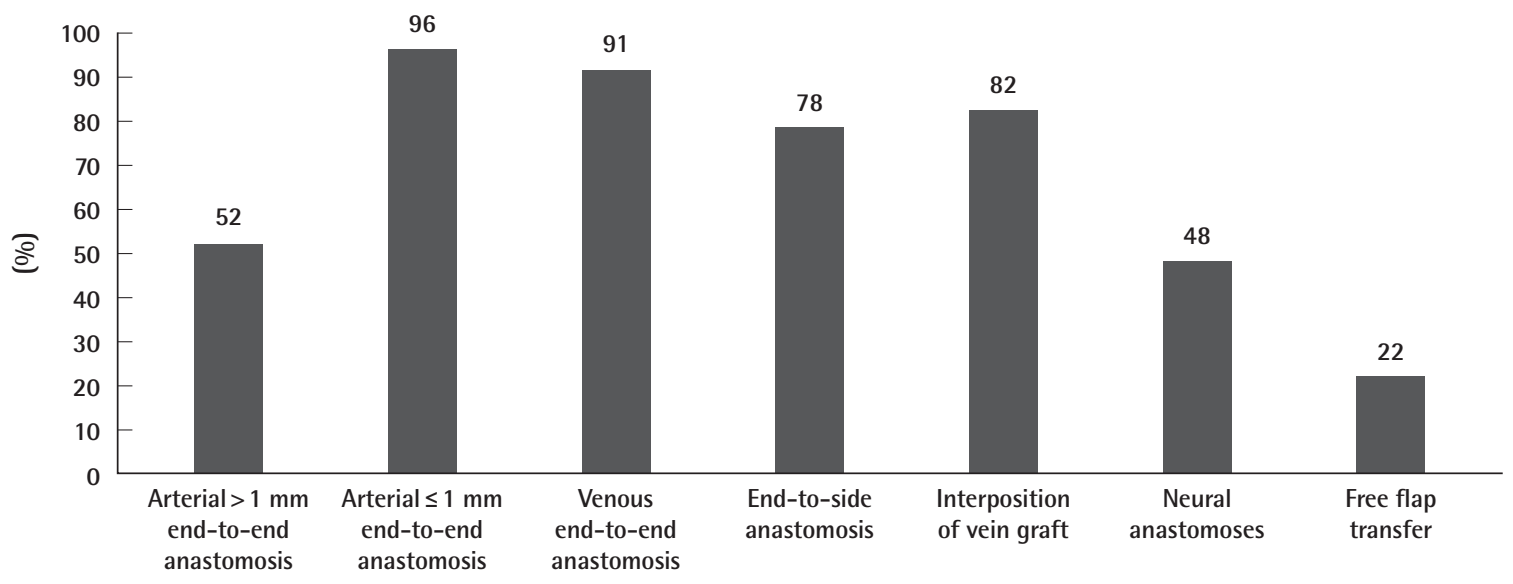


retraining of more established surgeons [14]. Interestingly, novices trained on low fidelity prosthetic models performed as well as those trained on high fidelity live rats [15]. Currently the most commonly used animal in microsurgical courses is the rat [16]. Trainees prefer cryo-preserved rat arteries over silicone tubes [17], and the former can be used for initial training exercises prior to progression in vivo models. The benefit of using in vivo models is that the normal clotting process is replicated. However, regulation of animal experimentation, increased scrutiny of the ethical use of laboratory animals, and the cost of maintaining an in vivo laboratory limit their availability.

As a result, microsurgery educators are being confronted by a compelling ethical argument to strongly apply Russell and Burch 3 R's of "Replacement, Refinement and Reduction" to the use of living animal models in microsurgery training courses [18]. Accordingly, and increasingly, it will be necessary to demonstrate the adherence to these ethical principles of replacing the animal models with synthetic or non-living models where possible, refining the conditions and the educational interventions for which living animals models would be used and reducing such animals to a minimum before microsurgery training courses would be authorised to include living animal models in its taught exercises as is the case in biomedical research [19]. For example, the UK's Animals (Scientific Procedures) Act 1986 aim to balance the legitimate needs of medical research and education with the welfare of the animals. This legislation applies to microsurgery education in the UK and restricts both the number of centres using living animals for microsurgery training and the number of animals used by each trainees by necessitating a certificate of designation (for the institution), a project licence (for the training programme) and a personal licence (for the student) before conducting microsurgery on living animals is authorised. This level of regulation would soon be the norm in Europe and worldwide. Currently, centres that provide living animal models as part of their training programmes are shown in Table 3.

Instruction in microvascular end-to-end and end-to-side anastomoses are common to most basic programmes, with half the courses offering practice on larger arteries $(>1 \mathrm{~mm}$ diameter) prior to practice on smaller arteries ( $\leq 1 \mathrm{~mm}$ diameter). However, instruction in interposition vein grafting, peripheral nerve repair, or flap transfer were not consistently offered. In vivo vascular models provide an opportunity for reviewing the functional results of anastomoses. Nerve models demand a different dissection and tissue handling. Thus with the variation in course costs , trainees should consider these factors.

The vast majority of centres did not make formal assessments of skill, skill acquisition or skill maintenance. Trainees receive guidance and feedback throughout the course and are given a certificate of completion, rather than one of competency. Criteriabased observation with checklists and GRS are more objective processes. Kalu et al. [20], adapted a checklist for end-to-end arterial anastomosis, but checklists demonstrate low levels of construct validity [21]. GRS consist of a number of important components of a task, such as suture handling, and are graded on a Likert scale with statements as anchor points. When used by trained assessors, GRS demonstrate good reliability and validity [22]. Grober et al. [23] developed a GRS for microsurgery. More recently, the University of Western Ontario Microsurgery Skills Acquisition/Assessment (UWOMSA) instrument was developed to assess microsurgical skill, in particular, knot tying and anastomosis [24]. Hand motion analysis (HMA) is another method for objective assessment of microsurgical skills [23], and it has been shown to correlate well with GRS and trainees with better dexterity scores produced vascular anastomoses that leaked less [25]. Vessel patency, an analysis of the final product in five centres (21\%), may be an important method of assessment because it is crucial for flap survival in successful microvascular free tissue transfer [26]. Szalay et al. [27] showed that novice surgeons had to performed between 40 and 48 vessel anastomoses to achieve $100 \%$ patency on live rats two weeks after the procedure. They also concluded that end product assessment on bench top models correlated well with GRS, time taken, and year of training. However, more research is required to determine whether which is more effective in assessing competency. Although assessments can be labour-intensive, it will become increasingly important to be able to gauge trainees' progress, and criteria-based tools can aid teaching and end-of-course evaluation.

There must be merits in the diversity of available courses whilst this area is in a process of development, but there is an increasing argument for standardisation of courses, and for more objective assessment measures of skill, skill acquisition and skill maintenance. Patients should have a reasonable expectation of consistent standards of surgical treatment. With the publications of medical errors and adverse events [28], training and certifying bodies are urged to develop new ways to show evidence of a surgeon's competence to ensure quality. Attendance of microsurgery courses and even operative experiences cannot lead us to presume that trainees have reached a certain level of competency $[29,30]$. A standardised training with formal assessments in competency must coexist [31]. In UK, the Joint Committee on Surgical Training (JCST) acts as an advisory body to develop quality assurance in surgical training, and through Intercollegiate Surgical Curriculum Programme (ISCP), it has worked towards a nationally standardised curriculum, which 
is underpinned by clearly defined standards and competencybased assessment for each stage of surgical training [32]. Similarly in colon and rectal surgery training in Europe, there are no minimum standards for training, no training unit recognition process, and no minimum time requirement for training in coloproctology. Plans are underway to define minimum standards of training to guarantee consistent standards of care [33]. Colorectal trainees would need to satisfy activity requirements for numbers of procedures, and to undergo procedure based assessments, along with examinations. Microsurgery training may benefit from looking at the system set up for endoscopy training. Endoscopy is house principally within medical and surgical gastroenterology, but radiologists, general practitioners and nurses also perform endoscopic procedures. The Joint Advisory Group (JAG) on gastrointestinal endoscopy (UK) was established in 1994 to provide quality assurance of endoscopy units, training and services [34]. All trainees in endoscopy must attend a JAG certified Basic Skills in Upper or Lower GI endoscopy course, which include formal instruction on indications and contraindications of endoscopic procedures, techniques of conscious sedation, maintenance, cleaning and disinfection of endoscopes and equipment, and recognition and management of complications. Training should only take place in units approved by the JAG, thus allowing for standardised training and assessment based on identical and agreed competences [35]. As we approach the era of surgical revalidation [36], standardisation in education and training would facilitate development and maintenance of microsurgical skills.

\section{REFERENCES}

1. Abreo N, Sivathasan N. Microsurgery training course, Columbia University, New York [Internet]. London: BMJ Careers; 2009 [cited 2012 Dec 18]. Available from: http://careers. bmj.com/careers/advice/view-article.html?id=20000467.

2. Goossens DP, Gruel SM, Rao VK. A survey of microsurgery training in the United States. Microsurgery 1990;11:2-4.

3. Izci Y, Timurkaynak E. A short history of the microsurgery training and research laboratory at Gulhane Military Medical Academy. Turk Neurosurg 2010;20:269-73.

4. Klein I, Steger U, Timmermann W, et al. Microsurgical training course for clinicians and scientists at a German University hospital: a 10-year experience. Microsurgery 2003; 23:461-5.

5. Mofikoya BO, Ugburo OA, Bankole OB. Challenges in the organisation of a microsurgery laboratory in a low resource country. Niger Postgrad Med J 2010;17:60-3.

6. Tadiparthi S. Microsurgery course [Internet]. London:
BMJ Careers; 2007 [cited 2012 Dec 18]. Available from: http://careers.bmj.com/careers/advice/view-articles.html$\mathrm{id}=2421$.

7. University of Sydney. Microsearch establishes new microsurgery course [Internet]. Sydney: Microserach Foundation of Australia; 2010 [cited 2012 Dec 18]. Available from: http://sydney.edu.au/medicine/foundation/microsearch/ publications/Newsletters/MicroNews_June10.pdf.

8. Wilson E. Inaugural European Louisville Microsurgery Course-Frankfurt [Internet]. London: BMJ Careers; 2008 [cited 2012 Dec 18]. Available from http://careers.bmj. com/careers/advice/view-articles.html-id=3176.

9. Yoong P. Microsurgery in India [Internet]. London: BMJ Careers; 2007 [cited 2012 Dec 18]. Available from http:// careers.bmj.com/careers/advice/view-articles.html-id=2566.

10. Starkes JL, Payk I, Hodges NJ. Developing a standardized test for the assessment of suturing skill in novice microsurgeons. Microsurgery 1998;18:19-22.

11. Atkins JL, Kalu PU, Lannon DA, et al. Training in microsurgical skills: does course-based learning deliver? Microsurgery 2005;25:481-5.

12. Studinger RM, Bradford MM, Jackson IT. Microsurgical training: Is it adequate for the operating room? Eur J Plast Surg 2005;28:91-3.

13. Lannon DA, Atkins JA, Butler PE. Non-vital, prosthetic, and virtual reality models of microsurgical training. Microsurgery 2001;21:389-93.

14. Peled IJ, Kaplan HY, Wexler MR. Microsilicone anastomoses. Ann Plast Surg 1983; 10:331-2.

15. Grober ED, Hamstra SJ, Wanzel KR, et al. The educational impact of bench model fidelity on the acquisition of technical skill: the use of clinically relevant outcome measures. Ann Surg 2004;240:374-81.

16. Berezniak R. Creating, developing and mastering a superior microsurgical technique. Reading, PA: Sharpoint; 1991.

17. Russell WM, Burch RL. The principles of humane experimental technique. London: Methuen; 1959.

18. Baumans V. Use of animals in experimental research: an ethical dilemma? Gene Ther 2004; 11 Suppl 1:S64-6.

19. Lausada NR, Escudero E, Lamonega R, et al. Use of cryopreserved rat arteries for microsurgical training. Microsurgery 2005;25:500-1.

20. Kalu PU, Atkins J, Baker D, et al. How do we assess microsurgical skill? Microsurgery 2005;25:25-9.

21. Taylor JB, Binenbaum G, Tapino P, et al. Microsurgical lab testing is a reliable method for assessing ophthalmology residents' surgical skills. Br J Ophthalmol 2007;91:1691-4.

22. Reznick R, Regehr G, MacRae H, et al. Testing technical 
skill via an innovative "bench station" examination. Am J Surg 1997; 173:226-30.

23. Grober ED, Hamstra SJ, Wanzel KR, et al. Validation of novel and objective measures of microsurgical skill: Handmotion analysis and stereoscopic visual acuity. Microsurgery 2003;23:317-22.

24. Temple CL, Ross DC. A new, validated instrument to evaluate competency in microsurgery: the University of Western Ontario Microsurgical Skills Acquisition/Assessment instrument. Plast Reconstr Surg 2011;127:215-22.

25. Datta V, Mandalia M, Mackay S, et al. Relationship between skill and outcome in the laboratory-based model. Surgery 2002;131:318-23.

26. Gardiner MD, Nanchahal J. Strategies to ensure success of microvascular free tissue transfer. J Plast Reconstr Aesthet Surg 2010;63:e665-73.

27. Szalay D, MacRae H, Regehr G, et al. Using operative outcome to assess technical skill. Am J Surg 2000;180:234-7.

28. Keogh B, Spiegelhalter D, Bailey A, et al. The legacy of Bristol: public disclosure of individual surgeons' results. BMJ 2004;329:450-4.

29. Lowry J, Cripps J. Results of the online EWTD trainee survey. Ann R Coll Surg Engl (Suppl) 2005;87:86-7.

30. Beard JD. Assessment of surgical skills of trainees in the UK. Ann R Coll Surg Engl 2008;90:282-5.
31. Reznick RK, MacRae H. Teaching surgical skills: changes in the wind. N Engl J Med 2006;355:2664-9.

32. Joint Committee on Surgical Training [Internet]. London: JCST; 2012 [cited 2013 Mar 03]. Available from: http:// www.jcst.org.

33. American Society of Colon \& Rectal Surgeons. Pan European Standardisation of Training in Colon and Rectal Surgery [Internet]. Arlington Heights, IL: ASCRS; c2013 [cited 2013 Mar 03]. Available from: http://www.fascrs.org/aboutus/international_iccp/international_training_standards/.

34. Joint Advisory Group on GI Endoscopy [Internet]. London; The JAG: 2013 [cited 2013 Mar 03]. Available from http:// www.thejag.org.uk/.

35. Association of Upper Gastrointestinal Surgeons of GB\&I (AUGIS) and Association of Coloproctology of GB\&I (ACPGBI). Recommendations for endoscopic training for gastrointestinal surgeons [Internet]. London: Association of Upper Gastrointestinal Surgeons of Great Britain and Ireland;2010 [cited 2013 Mar 03]. Available from http:// http://www.augis.org/pdf/reports/Combined_views_ on_endoscopic_training_for_surgeons_FINAL.pdf.

36. General Medical Council. Revalidation [Internet]. London: General Medical Council; 2013 [cited 2013 Mar 03]. Available from http://www.gmc-uk.org/doctors/revalidation.asp. 